\title{
Study of the Biceps Fatigue after Surgery on the Long Head of Biceps Tendon in Male Heavy Workers. A Prospective Randomized Clinical Trial Comparing Biomechanics and Clinical Outcomes after Tenotomy Versus Tenodesis
}

\author{
J. E. García-Rellan ${ }^{1,2}$, E. Sánchez-Alepuz ${ }^{3}$, J. Mudarra-García ${ }^{4}$, A. Silvestre ${ }^{4,5}$ \\ 1 Department for Orthopedics and Trauma Surgery, Clinic Hospital of Valencia, Valencia, Spain \\ 2 CEU-Cardenal Herrera University, Valencia, Spain \\ 3 Hospital of Unión de Mutuas, IMED Hospital, Valencia, Spain \\ ${ }^{4}$ Department for Orthopaedics and Trauma Surgery, Shoulder Unit, Clinic Hospital of Valencia, Valencia, Spain \\ 5 Surgery Department, School of Medicine, University of Valencia, Valencia, Spain
}

CORRESPONDING AUTHOR:

Jose E Garcia-Rellan

Clinic Hospital of Valencia

Blasco lbañez Sreet 17

46010, Valencia, Spain

CEU-Cardenal Herrera University

Alfara del Patriarca

46115 Valencia, Spain

E-mail: garcia_josrel@gva.es

DOI:

10.32098/mltj.03.2020.25

LEVEL OF EVIDENCE: 2B

\begin{abstract}
SUMMARY
The aim of this study was to evaluate biceps fatigue and strength after tenotomy vs tenodesis of the LHBT. The hypothesis was that there may be differences when analyzing biceps fatigue between both techniques.

Methods. 70 male heavy workers were initially enrolled to perform a biomechanical study. Preoperatively and 12 months after surgery a maximum elbow flexion force (MVC) and forearm supination test (MVS) were analyzed. Subsequently, a biceps fatigue test was performed by a submaximal contraction to $33 \%$ of MVC maintained until claudication. After the claudication, the MVC and MVS were measured again. In addition, the Constant score, SSI functional scale, VAS scale and perceived symptoms were evaluated. 45 patients met de inclusion criteria and were randomized into tenotomy or tenodesis group. 41 of them were followed-up for at least one year.

Results. There were no differences between groups at the end of the follow-up in MVC $(246.81 \pm 57,4$ vs $273.69 \pm 58,8 \mathrm{~N})$ nor in MVS $(50,73 \pm 6,31$ vs $177.7 \pm 71.6 \mathrm{Nm})$. The fatigue test was statistically shorter in the tenotomy group $(95.18 \pm 28.8$ vs $122.53 \pm 42.1 \mathrm{~s})$. Popeye sign was higher in the tenotomy group. There were no differences in postoperative pain, function scales, groove pain or biceps cramps.

Conclusions. The usual biomechanical study using maximum flexion or supination force has not seen differences, while the study of biceps fatigue has found them. The study of biceps fatigue is necessary to analyze the differences that with the standard study of maximum strength could be hidden.
\end{abstract}

\section{KEY WORDS}

Tenotomy; tenodesis; long head of biceps tendon; biomechanics; supination; fatigue.

\section{INTRODUCTION}

Tenotomy and tenodesis are the surgical techniques most commonly used in the treatment of the long head of the biceps tendon (LHBT) pathology. It is frequently associated with rotator cuff lesions due to the immunohistochemical pathogenesis that affects both tendons $(1,2)$. These can be carried out by arthroscopic techniques, when conser- vative options have failed. Both surgical techniques are widely known in the literature. The LHBT tenotomy $(3,4)$ is a simple and fast technique, with a short rehabilitation time and which produces good results in the functional assessment scales of the shoulder $(4,5)$. But this technique has a high prevalence of producing the Popeye sign (the distal retraction of the muscular belly of the biceps) $(6,7)$, 
the presence of muscle spasms and painful fatigue (8-10). The LHBT tenodesis $(9,11,12)$ reattaches the proximal stump of the tendon to prevent the descent of the muscular belly, maintaining tension-length relationship $(4,8)$, but it can produce pain in the place where the tenodesis is performed $(13,14)$.

The presence of muscle weakness after surgery on LHBT has been studied in numerous biomechanical articles using isometric $(5,13,15-20)$ and isokinetic (21-23) measurements. Some authors have reported cases of weakness of the peak flexion force of the elbow $(15,21,22,24)$ or forearm supination $(21,22)$ when the LHBT tenotomy is performed with respect to the healthy arm, although other authors have also noted deficits when performing tenodesis of the tendon $(13,17,18)$.

There are also articles that directly compare tenotomy with tenodesis $(13,17-21,24)$. Generally, the authors of the biomechanical articles base their studies on the measurement of the peak force of elbow flexion or forearm supination, but this may not be the most interesting parameter to know the functional result of the surgery on de LHBT, given that most of the of daily tasks are performed by repeated submaximal contractions (25). This is why other authors have based their biomechanical analysis on the quantification of fatigue of the biceps after the surgery on the LHBT, demonstrating early fatigue in cases operated by tenotomy, with respect to the healthy arm (26).

Therefore, a prospective randomized comparative clinical trial was designed analyzing biomechanical results of 2 different techniques for the treatment of the LHBT: tenotomy vs tenodesis. The aim of this study was to compare the biomechanical results of biceps fatigue (time to claudication) in the patients who underwent LHBT tenotomy in comparison to those who underwent tenodesis. We hypothesized that there would be significant differences in time to claudication among the techniques.

\section{METHODS}

The present study was approved by the ethics committees of both hospitals involved, and all the patients provided written informed consent to participate in this study, as required for publication (27). It was a prospective, randomized, controlled clinical trial who underwent arthroscopic repair of the LHBT lesions.

The inclusion criteria were the clinical or radiological diagnosis of LHBT pathology in men between 40 and 65 years of age. Patients older than 65 years as well as women were excluded from the study because they less frequently participated in intense physical work or intense sports activities, which may cause the sequelae to be less symptomatic.
Patients with previous history of contralateral upper limb pathology or with neuropsychiatric pathology were excluded. Associated concomitant injuries, such as those of the rotator cuff, were treated intraoperatively, and the lesion of the LHBT was reconfirmed intraoperatively, excluding from the study patients where the LHBT injury was absent or the lesion was small (less than $25 \%$ of the thickness of the tendon), where debridement of the tendon was performed. A total of 70 preoperative assessments of patients candidates for surgical treatment of LHBT were performed. Four patients were eliminated before randomization for not giving their consent for the study, and 21 patients for not meeting the selection criteria.

Randomization by blocks of 10 individuals from a total of 45 patients was carried out, assigning 24 subjects to the tenotomy group and 21 to the tenodesis group. The cases were analyzed by intention to treat. The principal investigator was unaware of the randomization sequence and the technique used until the end of the study. The technique assigned by the randomization process was introduced in a sealed envelope that prevented its reading before the moment of surgery. It was at the time of surgery, once the need to act on the LHBT was verified, when the sealed envelope was opened and the technique specified in the envelope was executed, without the presence of the examiner.

There was a loss of follow-up in 1 patient in the tenotomy group (contact was not achieved) and 3 in the tenodesis group (1 patient did not attend follow-up and 2 did not contact). The patient flow diagram is presented in figure $\mathbf{1}$. A total of 41 patients met the selection criteria and completed the biomechanical study 12 months after surgery. Patient demographic data and preoperative pain scores, functional scores and level of activity are detailed in table $\mathbf{I}$.

In addition with clinical interviews with the surgeon, an external investigator evaluated in the preoperative period all patients where pathology of the LHBT were suspected. If the LHBT injury was confirmed during surgery, the technique specified in the sealed envelope (tenotomy or tenodesis) was performed, and the external investigator examined the patient at 3, 6 and 12 months after surgery.

Population data, and International Physical Activity Questionnaire (IPAQ) responses were recorded in the interviews with the external examiner. Clinical examination was also performed using Shoulder Score Index (SSI) and normalized Constant Score, as well as anthropometric measurements including the presence of Popeye deformity, perceived satisfaction and a biomechanical test.

The biomechanical test (26) consisted of measuring the maximal voluntary flexion of the elbow, maximal voluntary supination of the forearm, a fatigue test, and maximal isometric flexion of the elbow and supination of the forearm 

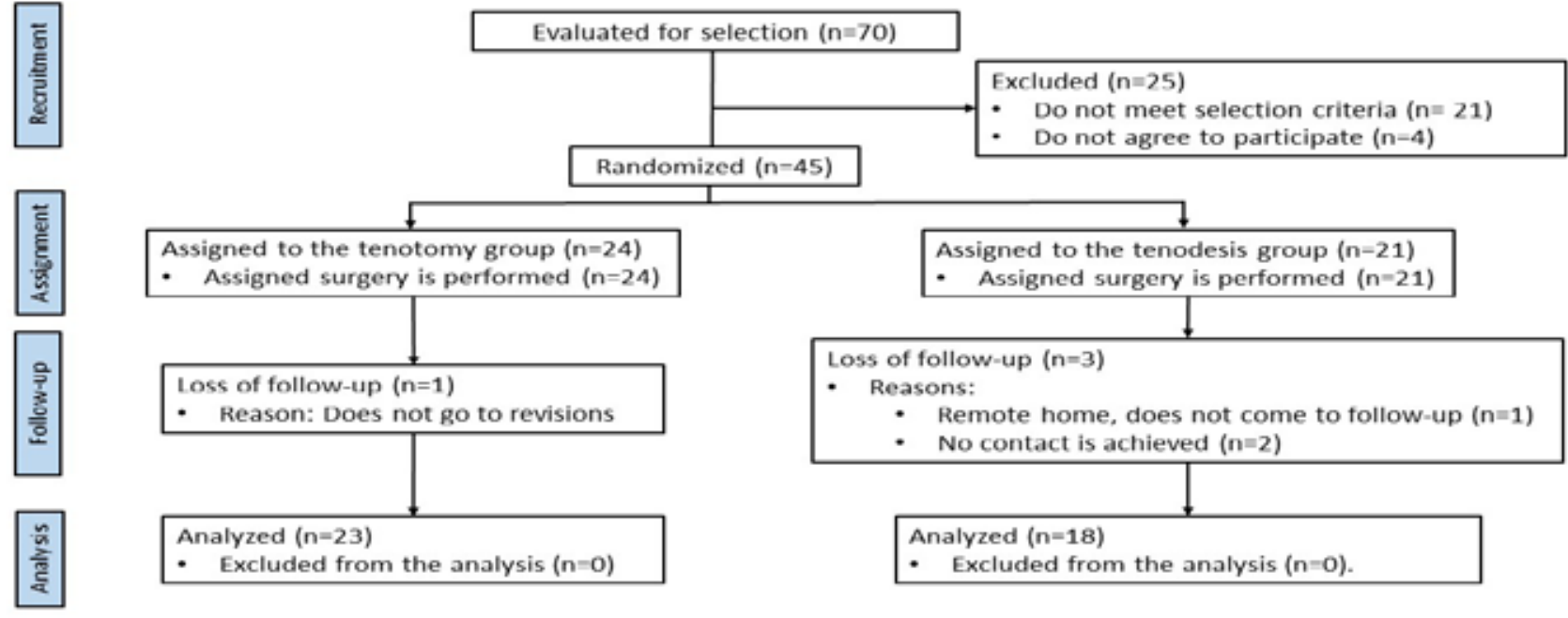

Figure 1. Flowchart of patients.

Table I. Demographic data before surgery in both groups.

\begin{tabular}{|c|c|c|c|}
\hline & $\begin{array}{l}\text { Tenotomy group } \\
(n=23)\end{array}$ & $\begin{array}{l}\text { Tenodesis group } \\
(\mathrm{n}=18)\end{array}$ & $\mathbf{p}$ \\
\hline Age & $54.7 \pm 5.78$ & $50.73 \pm 6.31$ & n.s. \\
\hline Affected shoulder & $\begin{array}{l}\text { Right: } 14(60.9 \%) \\
\text { Left: } 9(39.1 \%)\end{array}$ & $\begin{array}{l}\text { Right } 11(61.1 \%) \\
\text { Left } 7(38.9 \%)\end{array}$ & n.s. \\
\hline Dominance & $\begin{array}{l}\text { Yes: } 14(60.9 \%) \\
\text { No: } 9(39.1 \%)\end{array}$ & $\begin{array}{l}\text { Yes } 11(61.1 \%) \\
\text { No } 6(38.9 \%) \\
\end{array}$ & n.s. \\
\hline $\begin{array}{l}\text { Size of rotator cuff tear } \\
\cdot \text { Not affected } \\
\cdot \text { Small tear } \\
\cdot \text { Medium tear } \\
. \quad \text { Massive tear } \\
\end{array}$ & $\begin{array}{l}\mathrm{n}=1(4.3 \%) \\
\mathrm{n}=5(21.7 \%) \\
\mathrm{n}=10(43.5 \%) \\
\mathrm{n}=7(30.4 \%)\end{array}$ & $\begin{array}{l}\mathrm{n}=5(27.7 \%) \\
\mathrm{n}=3(16.6 \%) \\
\mathrm{n}=7(38.8 \%) \\
\mathrm{n}=3(16.6 \%)\end{array}$ & n.s. \\
\hline $\begin{array}{l}\text { Level of physical activity (METS) } \\
\text { Type of work: } \\
\cdot \text { Construction } \\
\cdot \text { Heavy machinery operator } \\
\cdot \text { Athletes } \\
\cdot \text { Marble, wood or metal workers } \\
\cdot \text { Security agent } \\
\cdot \text { Mechanics } \\
\cdot \text { Farmer } \\
\end{array}$ & $\begin{array}{l}14608.7 \pm 9454.5 \\
4(17.3 \%) \\
6(26 \%) \\
3(13 \%) \\
4(17.3 \%) \\
2(8.7 \%) \\
2(8.7 \%) \\
2(8.7 \%) \\
\end{array}$ & $\begin{array}{l}16282.6 \pm 11223.7 \\
3(16.7 \%) \\
4(22.2 \%) \\
2(11.1 \%) \\
3(16.7 \%) \\
3(16.7 \%) \\
2(11.1 \%) \\
1(5.5 \%) \\
\end{array}$ & n.s. \\
\hline BMI & $29.3 \pm 4.8$ & $29.2 \pm 3.3$ & n.s. \\
\hline Pain (VAS) & $7(3 ; 10)$ & $7(4 ; 10)$ & n.s. \\
\hline SSI & $43.33(12 ; 65)$ & $36.67(23 ; 72)$ & n.s. \\
\hline UCLA score & $20.50(12 ; 25)$ & $20(9 ; 26)$ & n.s. \\
\hline Normalized Constant & $70.43(29 ; 82)$ & $58.51(34.9 ; 93.75)$ & n.s. \\
\hline
\end{tabular}

BMI: Body mass index. VAS: visual analogue scale. SSI Shoulder score index. UCLA: The University of California Los Angeles shoulder score. VAS, Normalized Constant score, UCLA score and SSI scale are expressed in median and ranges. 
after-fatigue. Maximal voluntary contraction (MVC) of the elbow was determined in the patients while sitting in a chair, with the elbow flexed at $90^{\circ}$. MVC was determined with the forearm horizontal and in supination, with the transducer positioned on the wrist. The force exerted vertically was quantified using the Commander Muscle Testing dynamometer (JTECH Medical, Salt Lake City, USA) (figure 2), and the results were expressed in Newtons. The volunteers performed the maximal contraction test 3 times, trying to reach the highest value possible. The MVC was the largest parameter from among all exercises.

To measure maximal voluntary supination (MVS) force of the forearm a torsion dynamometer has been used (Baseline Hydraulic Wrist Dynamometer, FEI, White Plains, USA) (figure 3). The subject was evaluated while seated, with the elbow flexed at $90^{\circ}$, the forearm in pronation, and the hand grasping the lever of the torsion dynamometer. The results of the moment force were expressed in Newtons $\mathrm{x}$ m. The subjects performed three measurements on both elbows. The highest parameter of all the exercises was considered the MVS.

After performing the previous exercises, a submaximal isometric fatigue test $(26,28-33)$ was used. This test consisted of performing a contraction in isometric flexion on $33 \%$ of the MVC obtained previously, and was maintained as long as possible. The fatigue test concluded when the patient deviated from the target force by $-10 \%$ MVC force for more than $5 \mathrm{~s}$. When this occurred, the patient was deemed to have reached exhaustion. The time to claudication was observed in seconds and the patient was not aware of the result until the study was completely finished. Within $10 \mathrm{~s}$ after the fatigue test, MVC and MVS were performed again.

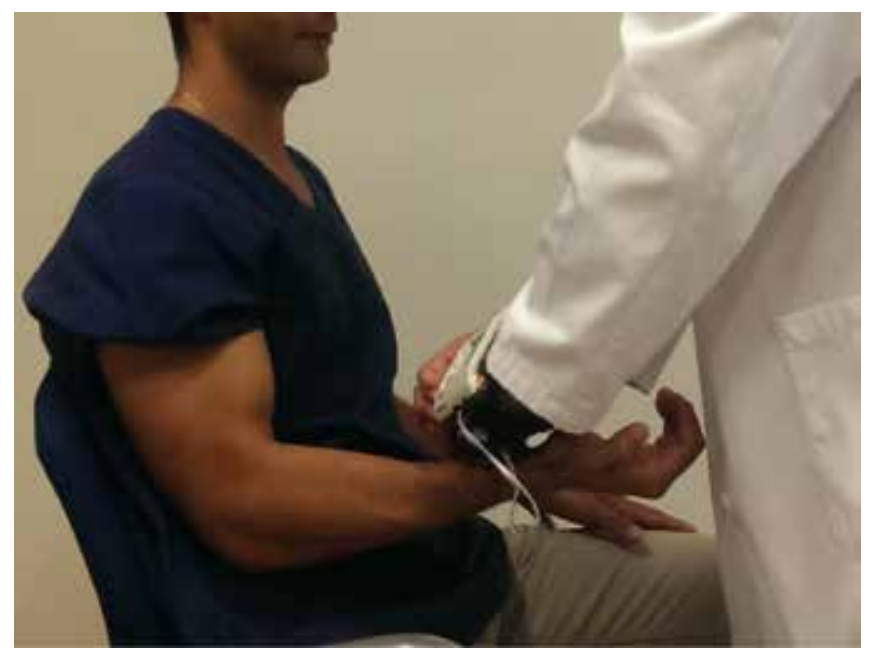

Figure 2. Commander muscle testing dinamometer
During the arthroscopy of the shoulder, a standard posterior and anterior portals were used to explore the joint. LHBT was evaluated for pathological changes at its insertion and also in the beginning of the bicipital groove. If there were others pathologic changes in the glenohumeral joint, they were managed first. In the tenotomy group, surgical technique was performed sectioning the LHBT near of its insertion with an electrocoagulator. The creation of a wide proximal stump was favored to facilitate the stop in the bicipital groove.

In the tenodesis group, all procedures conducted in the glenohumeral joint were similar except for the management of the LHBT. The tenodesis technique was performed by opening the bicipital slider, sectioning the transverse humeral ligament. The LHBT was extracted to appreciate the groove. The execution of the tenodesis was carried out $2 \mathrm{~cm}$ inferior to the upper vertex of the greater tuberosity, always inside the slide. The hole was carried out with the help of the Biceptor system (Smith \& Nephew, Andover, MA), using a guide wire for the realization of a hole of a diameter similar to the interferential screw to be used, and a length $0.5 \mathrm{~cm}$ longer. At that time, the tenotomy of the intraarticular portion of the tendon was performed similar to that defined in the tenotomy group. With the help of the fork of the Biceptor system, the tendon was introduced into the hole, favoring the sliding of the proximal part of the tendon, avoiding the overstretching. Then, the Biosure PK interferential screw (Smith \& Nephew, Andover, MA) was introduced and the remnant proximal stump was removed.

Routine postoperative rehabilitation protocol was performed. A sling was used during the first 3 weeks after surgery, allowing passive mobilizations of the shoulder and

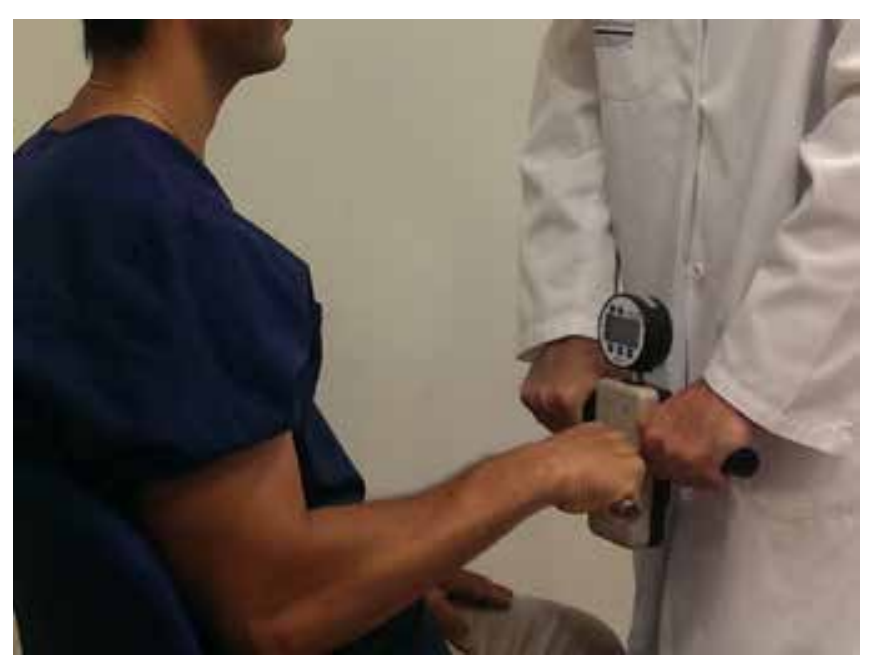

Figure 3. Baseline Hydraulic Wrist Torsion Dynamometer 
Table II. Clinical results 12 months after surgery.

\begin{tabular}{llll}
\hline & Tenotomy group & Tenodesis group & p \\
\hline Pain (VAS) & $2(0.8 ; 3.1)$ & $3(1.2 ; 4.8)$ & n.s. \\
\hline Normalized Constant score & $88.9(84.2 ; 93.5)$ & $89.7(82.4 ; 97)$ & n.s. \\
\hline SSI & $84.3(76.6 ; 92)$ & $76.1(63.8 ; 88.5)$ & n.s. \\
\hline UCLA score & $32.8(28.4 ; 37.1)$ & $31(28.3 ; 33.8)$ & n.s. \\
\hline Popeye sign & $56.5 \%$ & $11.1 \%$ & $0.01 *$ \\
\hline Residual groove pain & $18.2 \%$ & $27.7 \%$ & n.s. \\
\hline Biceps cramps & $14.3 \%$ & $22.2 \%$ & n.s. \\
\hline Perceived satisfaction & $90.9 \%$ & $100 \%$ & n.s. \\
\hline
\end{tabular}

VAS: visual analogue scale. SSI Shoulder score index. UCLA: The University of California Los Angeles shoulder score. VAS, normalized Constant score, SSI scale and UCLA score are expressed in median and ranges.

elbow. Gentle active arm movements were allowed from the third week until a full range of mobility was achieved.

The present study has been approved by the ethics committees of both hospitals: Hospital Clínico of Valencia (Spain) and Unión de Mutuas of Valencia (Spain).

\section{STATISTICS}

Prior to the beginning of the clinical trial, a retrospective pilot study (unpublished data) was conducted to know the variability of the main parameter to be measured in order to know the number of patients needed to be included in the study. The main parameter was established as the time in seconds until claudication when the elbow performs an isometric contraction at $90^{\circ}$ of flexion, maintaining the contraction at $33 \%$ of the Maximum Voluntary Contraction (in Newtons) previously collected. In this study it was determined that typical deviation of time to claudication was 37 seconds. To detect a measurement difference of 40 seconds ( $30 \%$ of the average fatigue time), using a significance level $\alpha=0$ '05 with a power of $80 \%$ and assuming a standard deviation of 37 seconds, it was necessary to observe 13 patients per group, 26 in total.

The SPSS 15.0 program (SPSS Inc, Chicago, IL) has been used for the analysis of the data collected from the sample. An exploratory analysis of the database has been carried out using basic statistical techniques descriptive in both treatment groups, and expressed the quantitative variables in the form of mean \pm standard deviation, and the qualitative variables in absolute number and percentage of the total. The normality of the numerical variables was analyzed using the Kolmogórov-Smirnov test.

For the assessment of the proposed objectives, statistical group comparison techniques have been used. Specifically, for the comparison of continuous variables between the two groups, we used the t-Student test or its nonparametric alternative, Mann-Whitney $U$, according to the result of the normality test. For the comparison of proportions, the Chi-square test or its nonparametric alternative, Fisher's exact test, was used, depending on the number of cases. In some cases, and according to the normality of the variables, the dispersion of the data has been expressed, expressing the $95 \%$ confidence interval.

\section{RESULTS}

Demographic data about groups is expressed in table I. Differences in the base groups have been analyzed for later comparison.

In the comparative study of both techniques 12 months after the surgery, a similar result can be seen in terms of clinical pain parameters, the Constant score and SSI and UCLA scales. Additionally, there were no differences between both techniques in residual groove pain, biceps cramps or perceived satisfaction. Nevertheless, Popeye sign was statistically higher in tenotomy group. These results are displayed in table II, showing clinical values between techniques 12 months after surgery.

Biomechanical data are expressed in tables III and IV. A significant increase has been proved in MVC in both groups with respect to the preoperative values, both in the pre-fatigue study and in the after-fatigue study. This increase with respect to the preoperative values has also been seen in the measurement of the MVS, except in the tenotomy group in the pre-fatigue measurement, where no differences have been found. A significant loss of fatigue time (time to claudication) was found in the group where LHBT tenotomy was performed (decrease from $139.1 \pm 71.6 \mathrm{~s}$ to $95.18 \pm 28.8 \mathrm{~s}$; p < $<.01$ ). This deficit has not been evidenced in the group where tenodesis was performed $(137.6 \pm 99.2 \mathrm{~s}$ in the preoperative 
Table III. Biomechanical results 12 months after surgery.

\begin{tabular}{llll}
\hline & Tenotomy group & Tenodesis group & p \\
\hline MVC at rest $(\mathrm{N})$ & $246.81 \pm 57.4$ & $273.69 \pm 58.8$ & n.s. \\
\hline MVS at rest $(\mathrm{Nm})$ & $147.5 \pm 56,98$ & $177.7 \pm 71.6$ & n.s. \\
\hline Fatigue time $(\mathrm{s})$ & $95.18 \pm 28.8$ & $122.53 \pm 42.1$ & $0.03^{*}$ \\
\hline MVC after-fatigue $(\mathrm{N})$ & $207.3 \pm 51.8$ & $219.3 \pm 65.77$ & n.s. \\
\hline MVS after-fatigue $(\mathrm{Nm})$ & $137.1 \pm 49.9$ & $194.7 \pm 72.9$ & $0.01^{*}$ \\
\hline
\end{tabular}

MVC: Maximal voluntary contraction (in elbow flexion). MVS: Maximal voluntary supination (of the forearm).

Table IV. Differences in biomechanics before and after surgery.

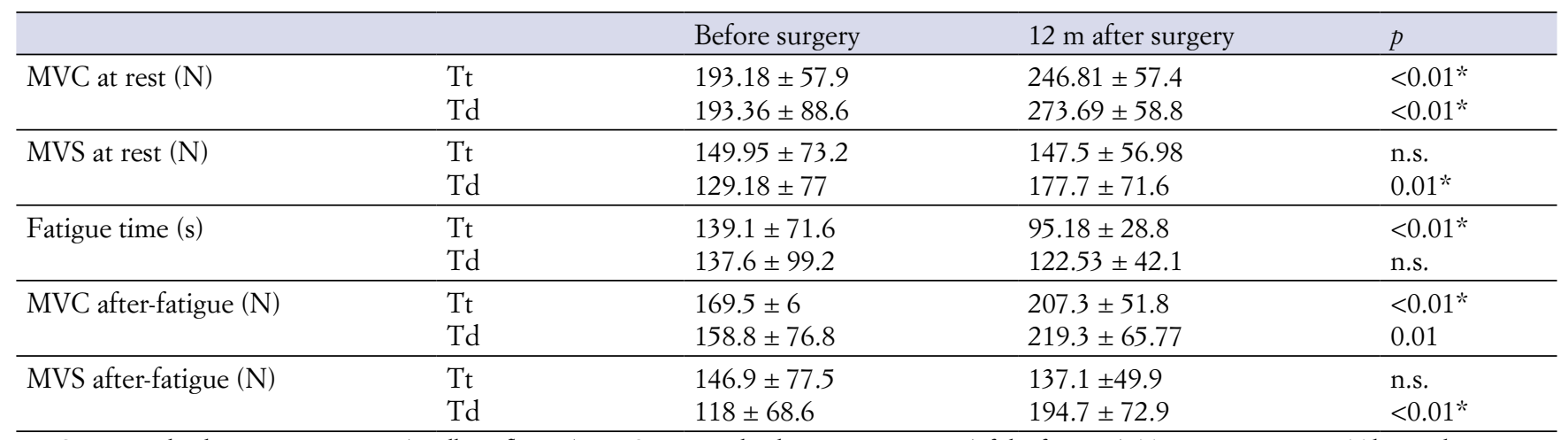

MVC: Maximal voluntary contraction (in elbow flexion). MVS: Maximal voluntary supination (of the forearm). Tt: tenotomy group. Td: tenodesis group.

period and $122.53 \pm 42.1 \mathrm{~s}$ at the end of the follow-up; $\mathrm{p}=$ n.s.). Statistical differences were found between groups at the end of the follow-up in terms of fatigue time (95.18 \pm 28.8 s vs. $122.53 \pm 42.1 ; \mathrm{p}=0.03$ ).

\section{DISCUSSION}

The most important finding in this study has been the difference in fatigue time between groups found at the end of the follow-up $(95.18 \pm 28.8 \mathrm{~s}$ in the tenotomy group vs $122.53 \pm 42.1 \mathrm{~s}$ in the tenodesis group; $\mathrm{p}=0.03$ ). To date, no clinical trial has focused on the study of biceps fatigue as the main study parameter. The different biomechanical studies carried out to date analyze the results of the surgery based on the analysis of basic biomechanical parameters (MVC, MVS). Maximum peak force in elbow flexion or supination of the forearm are important biomechanical parameters, but they may not be the most relevant parameters in clinical practice, because most of the daily activities are performed by repeated submaximal contractions (25).

There is controversy in whether there is a decrease in MVC or MVS after the surgery on the LHBT. There are different studies that show a decrease in flexion strength between
$4.4 \%$ and $14 \%(15,21,22,24)$ in patients where tenotomy where performed with respect to the healthy arm. But this decrease is very similar to the data provided by studies that analyze patients undergoing tenodesis with respect to the healthy arm (decrease between 9\% and 15\%)(21,22). Shank et al. (21) and Sentürk et al. (23) studied the biomechanical differences between patients undergoing tenotomy or tenodesis of LHBT. Both authors, using the Cybex isokinetic dynamometer, found no differences in flexion strength or supination. In the same way, other authors have also not found differences when manual dynamometers were used. Lee et al. (19) and Oh et al. (20) did not find differences between groups in flexion, but in supination, in favor of performing tenodesis.

In the present study, no differences in pre-fatigue flexion strength were observed between the groups $(246.81 \pm 57.4$ $\mathrm{N}$ vs $273.69 \pm 58.8 \mathrm{~N}$ ), nor in the pre-fatigue supination force of the forearm $(147.5 \pm 56.98 \mathrm{~N}$ vs $177.7 \pm 71.6 \mathrm{~N})$.

Generally, force measurements in biomechanical studies are analyzed with the arm in baseline (not fatigued). Friedman et al. (13) trying to find differences between tenotomy and tenodesis, analyzed the MVC and MVS in the fatigued $\mathrm{arm}$. For this, they performed a fatigue test by lifting dumbbells and subsequently quantified the MVC and the MVS 
in the fatigued arm, without finding differences between the groups. In the present study, no differences were found between groups in the after-fatigue MVC $(207.3 \pm 51.8 \mathrm{~N}$ vs. $219.3 \pm 65.77 \mathrm{~N})$, but statistical differences have been observed in the after-fatigue MVS $(137.1 \pm 49.9 \mathrm{~N}$ vs. 194.7 $\pm 72.9 \mathrm{~N} ; \mathrm{p}=0.01$ ). These differences were not appreciated in the pre-fatigue study. This suggests that the biomechanical study in the fatigued arm is useful for demonstrating differences that were not appreciated with the arm at baseline. This particularity in the biomechanical measurement after-fatigue has its relevance in the clinic, given that manual workers do not carry out their job in a baseline situation, but are progressively more fatigued when performing their workday.

It is interesting to note that in the present study differences between groups in after-fatigue supination force were observed (table III), while no differences were observed in terms of muscle cramps or residual pain in the slider (table II). This suggests that the strength deficit is not related to pain. This supination deficit was only seen in the after-fatigue study. This means that, in basal conditions (non-fatigued arm), the generation of supination force does not differ between the groups, while differences in time to claudication and supination force after fatigue have been found. An electromyographic study of the operated patients could determine if the deficit is due to a failure in neuromuscular transmission (inhibition of the motor neuron, central fatigue) or if it is due by a cellular cause (peripheral fatigue).

To date, no author has focused the study on fatigue time until biceps claudication when analyzing the differences between tenotomy and LHBT tenodesis.

Some authors have tried to make an approximation to biceps fatigue by lifting dumbbells, measuring the number of repetitions until claudication of the arm. Kelly et al. (9) appreciated differences in the number of elevations two years after performing biceps tenotomy (32.3 repetitions) compared to the healthy arm ( 34.5 repetitions). In a similar way, Drakos et al. (34) did not appreciate differences in the number of dumbbell elevations in the arm where the tenodesis was performed (33.2 repetitions) with respect to the healthy arm (34.3 repetitions).

Using dumbbells to perform the fatigue test is an easy, accessible and reproducible way to perform the biomechanical test, but it can lead to bias. This is because it does not report the test time or the frequency of repetitions. It does not take into account the biomechanical characteristics of each subject (all subjects lift 10lbs without taking into account biometrics) nor do the authors report the position of the forearm during the dumbbell lift. Other studies induce biceps fatigue by isometric contraction of the elbow, using a manual dynamometer $(28,31,32,35)$. To do this, the MVC is determined first and, depending on it, perform a submaximal percentage isometric contraction maintained over time. This fatigue induction model has been used in basic studies and also in studies that analyze the results after the surgery on $\mathrm{LHBT}^{26}$. This biceps fatigue induction model has been used in the present study. It estimates the fatigue test based on the biomechanical characteristics of the individual, in a dynamic way over time, according to their MVC. It pays special attention to the duration of the test until the claudication and allows the performance of the MVC and the MVS after-fatigue. The study of the time until claudication after performing the surgical techniques on LHBT has clinical relevance because it provides information on the possible fatigue of the biceps in patients who require a physical activity maintained during the workday. This must be taken into account for the choice of surgical technique on the LHBT by the surgeon.

Avoiding the Popeye sign is one of the reasons why LHBT tenodesis is performed. In a recent systematic review, Slenker et al. (6) quantified this deformity in $42 \%$ of the patients where tenotomy had been performed, compared to $8 \%$ of the patients operated by tenodesis. In the present study, this difference between groups has been significant $56.5 \%$ vs. $11.1 \%$; $=0.01$ ). The data obtained have been similar to other studies in the literature $(5,9,13,20,36)$, but slightly higher than those provided by the systematic review. This can be justified by the mean age $(50.73 \pm 6.31$ years in the tenodesis group), lower than in the systematic review (over 60 years). It can also be justified by the male sex of all subjects, more prone to deformity after surgery on the LHBT $(9,15,20,37)$. There were no differences between groups in terms of pain (VAS), functional scales (normalized Constant score, SSI, UCLA), residual pain in the slide, biceps cramps or perceived satisfaction.

It has been analyzed whether in the presence of aesthetic deformity there are differences in function, pain, side effects or biomechanical parameters with respect to subjects without deformity. In the function scales, differences were found in favor of the group with deformity in the SSI scale (75.68 \pm 18.54 in the group without deformity vs $89.44 \pm 18.15$ in the group with deformity; $\mathrm{p}=0.03$ ), but not in normalized Constant score nor UCLA. No differences were observed in terms of pain, muscle cramps, pain in the slide or biomechanical parameters.

The evolution of postoperative pain after LHBT surgery is a parameter to be taken into account, because a higher incidence of initial surgical pain has been observed in patients where tenodesis have been performed ${ }^{7}$. In the present study, there were no differences in the VAS scale in the postoperative period at 3 months $(3.06 \pm 2.28$ in tenotomies vs 4.33 
\pm 2.28 in tenodesis), 6 months $(2.67 \pm 2.49$ vs $2.83 \pm 2.44)$, nor at 12 months. $(2 \pm 2.65$ vs $3 \pm 2.97)$.

In this study some methodological weaknesses have been assumed. The first is the small sample size. Although the population studied is small, it reaches the minimum required by the power study that was conducted prior to the clinical trial. The second weakness is the short period of follow-up of patients (1 year). Longer temporal evolution can lead to adaptive changes that modify the clinical and biomechanical results. There is also a weakness induced by the age range of the sample studied and sex. This can lead to bias in extrapolation of data to the general population.

As mentioned in this discussion section, the results of this clinical trial are important in daily clinical practice, because they offer biomechanical and clinical data to be taken into account in the choice of surgical technique to be used in the pathology of LHBT.

\section{REFERENCES}

1. Oliva F, Piccirilli E, Bossa M, et al. I.S.Mu.L.T - Rotator Cuff Tears Guidelines. Muscles, ligaments and tendons journal 2015;5:227-63.

2. Cipollaro L, Sahemey R, Oliva F, Maffulli N. Immunohistochemical features of rotator cuff tendinopathy. British medical bulletin 2019;130:105-23.

3. Maynou C, Mehdi N, Cassagnaud X, Audebert S, Mestdagh $H$. [Clinical results of arthroscopic tenotomy of the long head of the biceps brachii in full thickness tears of the rotator cuff without repair: 40 cases]. Rev Chir Orthop Reparatrice Appar Mot 2005;91:300-6.

4. Walch G, Edwards TB, Boulahia A, Nove-Josserand L, Neyton L, Szabo I. Arthroscopic tenotomy of the long head of the biceps in the treatment of rotator cuff tears: clinical and radiographic results of 307 cases. J Shoulder Elbow Surg 2005;14:238-46.

5. Duff SJ, Campbell PT. Patient acceptance of long head of biceps brachii tenotomy. J Shoulder Elbow Surg 2012;21:61-5.

6. 6.Slenker NR, Lawson K, Ciccotti MG, Dodson CC, Cohen SB. Biceps tenotomy versus tenodesis: clinical outcomes. Arthroscopy 2012;28:576-82.

7. 7.Hsu AR, Ghodadra NS, Provencher MT, Lewis PB, Bach BR. Biceps tenotomy versus tenodesis: a review of clinical outcomes and biomechanical results. J Shoulder Elbow Surg 2011;20:326-32.

8. Boileau P, Baque F, Valerio L, Ahrens P, Chuinard C, Trojani C. Isolated arthroscopic biceps tenotomy or tenodesis improves symptoms in patients with massive irreparable rotator cuff tears. J Bone Joint Surg Am 2007;89:747-57.

9. Kelly AM, Drakos MC, Fealy S, Taylor SA, O'Brien SJ. Arthroscopic release of the long head of the biceps tendon: functional outcome and clinical results. Am J Sports Med 2005;33:208-13.

10. Carroll RE HLRotbbacmotJBSA.

\section{CONCLUSIONS}

The most important finding of this study was that differences in fatigue time were found between the tenotomy and tenodesis groups at 12 months after the intervention.

Differences were seen in the MVS after-fatigue in favor of performing tenodesis. No differences were found in the study of MVC or MVS before fatigue.

The study of fatigue should be considered in subsequent biomechanical studies.

Clinical relevance. Despite of the absence of differences in the maximum strength of flexion or supination of the elbow, the presence of early fatigue in the tenotomy group should be taken into account when choosing the surgical technique on LHBT.

\section{CONFLICT OF INTERESTS}

The authors declare that they have no conflict of interests.

11. Berlemann U, Bayley I. Tenodesis of the long head of biceps brachii in the painful shoulder: improving results in the long term. J Shoulder Elbow Surg 1995;4:429-35.

12. Boileau P, Krishnan SG, Coste JS, Walch G. Arthroscopic biceps tenodesis: a new technique using bioabsorbable interference screw fixation. Arthroscopy 2002;18:1002-12.

13. Friedman JL, FitzPatrick JL, Rylander LS, Bennett C, Vidal AF, McCarty EC. Biceps Tenotomy Versus Tenodesis in Active Patients Younger Than 55 Years: Is There a Difference in Strength and Outcomes? Orthop J Sports Med 2015;3:2325967115570848.

14. Franceschi F, Longo UG, Ruzzini L, Papalia R, Rizzello G, Denaro V. To detach the long head of the biceps tendon after tenodesis or not: outcome analysis at the 4-year follow-up of two different techniques. Int Orthop 2007;31:537-45.

15. Lim TK, Moon ES, Koh KH, Yoo JC. Patient-related factors and complications after arthroscopic tenotomy of the long head of the biceps tendon. Am J Sports Med 2011;39:783-9.

16. De Carli A, Zanzotto E, Vadala AP, Luzon D, Di Salvo M, Ferretti A. Surgical repair of the distal biceps brachii tendon: clinical and isokinetic long-term follow-up. Knee surgery, sports traumatology, arthroscopy : official journal of the ESSKA 2009; 17:850-6.

17. Koh KH, Ahn JH, Kim SM, Yoo JC. Treatment of biceps tendon lesions in the setting of rotator cuff tears: prospective cohort study of tenotomy versus tenodesis. Am J Sports Med 2010;38:1584-90.

18. Zhang Q, Zhou J, Ge H, Cheng B. Tenotomy or tenodesis for long head biceps lesions in shoulders with reparable rotator cuff tears: a prospective randomised trial. Knee surgery, sports traumatology, arthroscopy : official journal of the ESSKA 2015;23:464-9.

19. Lee HJ, Jeong JY, Kim CK, Kim YS. Surgical treatment of lesions of the long head of the biceps brachii tendon with rota- 
tor cuff tear: a prospective randomized clinical trial comparing the clinical results of tenotomy and tenodesis. J Shoulder Elbow Surg 2016;25:1107-14.

20. Oh JH, Lee YH, Kim SH, et al. Comparison of Treatments for Superior Labrum-Biceps Complex Lesions With Concomitant Rotator Cuff Repair: A Prospective, Randomized, Comparative Analysis of Debridement, Biceps Tenotomy, and Biceps Tenodesis. Arthroscopy 2016;32:958-67.

21. Shank JR, Singleton SB, Braun S, et al. A comparison of forearm supination and elbow flexion strength in patients with long head of the biceps tenotomy or tenodesis. Arthroscopy 2011;27:9-16.

22. The B, Brutty M, Wang A, Campbell PT, Halliday MJ, Ackland TR. Long-term functional results and isokinetic strength evaluation after arthroscopic tenotomy of the long head of biceps tendon. Int J Shoulder Surg 2014;8:76-80.

23. Senturk I, Ozalay M, Akpinar S, Leblebici B, Cinar BM, Tuncay C. Clinical and isokinetic comparison between tenotomy and tenodesis in biceps pathologies. Acta Orthop Traumatol Turc 2011;45:41-6.

24. De Carli A, Vadala A, Zanzotto E, et al. Reparable rotator cuff tears with concomitant long-head biceps lesions: tenotomy or tenotomy/tenodesis? Knee surgery, sports traumatology, arthroscopy : official journal of the ESSKA 2012;20:2553-8.

25. Grabiner MD, Enoka RM. Changes in movement capabilities with aging. Exerc Sport Sci Rev 1995;23:65-104.

26. Garcia-Rellan JE, Sanchez-Alepuz E，Mudarra-Garcia $\mathrm{J}$. Increased fatigue of the biceps after tenotomy of the long head of biceps tendon. Knee surgery, sports traumatology, arthroscopy : official journal of the ESSKA 2018;26:3826-31.

27. Padulo J, Oliva F, Frizziero A, Maffulli N. Muscles, Ligaments and Tendons Journal - Basic principles and recommendations in clinical and field Science Research: 2016 Update. Muscles, ligaments and tendons journal 2016;6:1-5.
28. Seghers J, Spaepen A, Delecluse C, Colman V. Habitual level of physical activity and muscle fatigue of the elbow flexor muscles in older men. Eur J Appl Physiol 2003;89:427-34.

29. Bilodeau M, Henderson TK, Nolta BE, Pursley PJ, Sandfort GL. Effect of aging on fatigue characteristics of elbow flexor muscles during sustained submaximal contraction. J Appl Physiol (1985) 2001;91:2654-64.

30. Hunter SK, Enoka RM. Sex differences in the fatigability of arm muscles depends on absolute force during isometric contractions. J Appl Physiol (1985) 2001;91:2686-94.

31. Hunter SK, Critchlow A, Shin IS, Enoka RM. Fatigability of the elbow flexor muscles for a sustained submaximal contraction is similar in men and women matched for strength. J Appl Physiol (1985) 2004;96:195-202.

32. Hunter SK, Critchlow A, Enoka RM. Muscle endurance is greater for old men compared with strength-matched young men. J Appl Physiol (1985) 2005;99:890-7.

33. Bilodeau M, Erb MD, Nichols JM, Joiner KL, Weeks JB. Fatigue of elbow flexor muscles in younger and older adults. Muscle Nerve 2001;24:98-106.

34. Drakos MC, Verma NN, Gulotta LV, et al. Arthroscopic transfer of the long head of the biceps tendon: functional outcome and clinical results. Arthroscopy 2008;24:217-23.

35. Fuglevand AJ, Zackowski KM, Huey KA, Enoka RM. Impairment of neuromuscular propagation during human fatiguing contractions at submaximal forces. J Physiol 1993;460:549-72.

36. Franceschi F, Longo UG, Ruzzini L, Rizzello G, Maffulli N, Denaro V. No advantages in repairing a type II superior labrum anterior and posterior (SLAP) lesion when associated with rotator cuff repair in patients over age 50: a randomized controlled trial. Am J Sports Med 2008;36:247-53.

37. Biz C, Vinanti GB, Rossato A, Arnaldi E, Aldegheri R. Prospective study of three surgical procedures for long head biceps tendinopathy associated with rotator cuff tears. Muscles, ligaments and tendons journal 2012;2:133- 